\title{
Crop Evolution and Domestication Syndromes
}

\author{
Abenezer Abebe Amaru Ushecho \\ Jimma University, Department of plant science and Horticulture
}

\begin{abstract}
Crops evolved through evolution and domestication process and different crops either have different or similar origin. Evolution and domestication process is progressing process starting with wild species, then formation of cultivated one and selection of improved strain of the species by growers and researchers. These processes may happen due to mutation, immigration, artificial selection, natural selection, speciation and cross. Evolution and domestication process then results difference among domesticated as well as evolved crops from their wild progenitors and this coined as syndromes. The syndromes discussed in this paper includes plant height and growth habit, flowering time inflorescence size and morphology, fruit size and morphology, organ color and toxic substance, seed size and dispersal and seed dormancy. As future direction, studying the wild species more and more and maintaining them enables to develop crops that are resist to biotic or abiotic stresses and obtaining yielding crops varieties.
\end{abstract}

Keywords: Crop, Evolution, Domestication, Syndrome

DOI: $10.7176 / \mathrm{JNSR} / 9-12-01$

Publication date:June $30^{\text {th }} 2019$

\section{Introduction}

Crop is anything that harvested for food, livestock, fuel and industry and further divided into four categories: wild, tolerated, encouraged, and domesticated Harlan (1992) defines. Evolution is the process of biological and organic change within the plant kingdom by which the characteristics of plants differ from generation to generation. Comparing among living plants, and fossil record have been critical in dating evolutionary events and revealing extinct intermediates between modern groups, which are separated from each other by great morphological gaps. It happens due to mutation, immigration, artificial selection, natural selection, and speciation (Parmesan, 2006).

Agriculture is a major innovation of human kind and its development had dramatic impact on environment and society (history, power, political, creativity) and allowed human to develop other innovations and structures that bring a change. Agriculture is the systematic raising of useful plants and livestock under the management of man (Rimando, 2004). Crop Science 1: Fundamentals of Crop Science. U.P. Los Baños: University Over the years, the evolution of crop plants has been a topic of great interest to crop scientists and evolutionary biologists alike. Crop evolution thus serves as a useful model for investigating the molecular basis of adaptive trait evolution (Hancock, 2005; Ross-Ibarra et al, 2007).

Crop domestication is the process by which crops are genetically modified over time by humans for traits that are more advantageous or desirable for humans. Domestication performed by humans primarily during the last 10,000 years is a great evolutionary experiment of adaptation and speciation generating beginner species (Darwin, 1905; Zohary and Hopf, 2000; Feldman and Kislev, 2007). It leads to adaptive syndromes fitting human ecology (Harlan, 1992). Darwin (1868) observed that 'No doubt man selects varying individuals, sows their seeds, and again selects their varying offspring. The traits selected for are advantageous to humans but not necessarily advantageous for the plants; these newly developed plants have often lost the ability to survive in the wild without humans. For instance, the large kernels of contemporary maize ears are not easily dispersed by wind or birds. Some domesticated plants seed may not disperse through ingestion by animals like their ancestors do because of their hard coat lost thoroughly digested such that they are no longer viable when expelled through feces. These differences between domesticated as well as evolved plants and their wild progenitors termed as syndromes.

Evolution and domestication process is progressing process starting with wild species, then formation of the cultivated one and selection of improved strain of the species by growers (landraces) and modern cultivars. Evolution continues through domestication and even today, different crop species could evolve into new species new. Particularly, new gen from the same species, and novel genes from any species are being introduced to our current crops. An understanding of genetics and breeding concepts and methodologies and of domestication can help us manage the genetic resources that are available for the various crops and how to use this diversity for crop improvement(Flint-Garcia, 2013).Therefore, particularly understanding or having knowledge about crop evolution and domestication history, process leads, syndromes, impact or and future possibility is indispensible

\section{Objective \\ - To review crop evolution and domestication syndromes and their suitability over the wild for farming.}




\section{Literature review \\ Origin of cultivated crops}

In the 19th century de Candolle (1959) first develop hypotheses for determining centers of origin for the various crop species using evidence from multiple disciplines (botany, geography, history, linguistics, and archaeology). According to Vavilov (1992) eight centers of crop origins were discovered based on morphological similarities between wild species and crop plants or the number of cultivars or varieties of a crop species and these centers were Tropical South Asiatic, East Asiatic, Southwestern Asiatic, Western Asiatic, Mediterranean, Abyssinian [Ethiopian], Central American, and Andean-South American. Besides, he developed the idea of secondary centers for crops that did not fit well into his defined centers of origin. This help us for studying the origins of crop plants, but perhaps his greatest contribution was his idea to collect the wild relatives of crop plants from these areas so they could be used in plant breeding programs for crop improvement. Now a day researchers are using de Candolle's multidisciplinary approach by using advances in carbon dating and molecular techniques as well as archaeological (Kirch, 2000) and linguistic data (Diamond and Bellwood, 2003) and building on the hypotheses of Vavilov and Harlan to study crop origins and dispersal. Based on our present knowledge, where are the centers of origin Maize, papaya, cassava, cacao, avocado, beans (Phaseolus spp.), chayote, squash, cotton, and chili peppers have their origins in Mesoamerica. In the Old World, African rice (Oryza glaberrima), coffee, beans (Vigna spp. and Lablab niger), pearl millet (Pennisetumglaucum), finger millet (Eleusinian coracana), sorghum, watermelon, yams, and sesame are attributed to central Africa. Crops like apples, barley, beans (Vicia spp.), lentils, olives, peas, pears, wheat, pomegranates, onions, grapes, figs, and dates were first brought into cultivation at Fertile Crescent of the Mediterranean(Maxted and Given, 2005)

\section{Crop Evolution and domestication}

Evolution claims that plants descended from algae as they colonized the empty landmass. Plants couldn't have evolved until there was a sufficient ozone layer to block radiation. The many structures that plants require in order to overcome gravity, keep from drying out, and reproduce would have to have developed gradually over millions of years. The simple groups are evolutionary dead ends; so plants must have evolved simultaneously in several different ways. Seed plants are alleged to have had an advantage over other ancient plants, and they dominated the landscape (Beerling, 2007).

The vascular plants are supposed to have evolved separately from other algae. The ferns, club mosses, and horsetails (pteridophytes) are the suggested common ancestors to the vascular plants that are present in large quantities today (Stewart and Rothwell., 1993). Seed plants (Spermatophyta) comprise two major groups: the Acrogymnospermae (also referred to as gymnosperms; c. 800 living species) and the Angiospermae (also referred to as angiosperms; c. 250000 living species) (Cantino et al., 2007). Although many seed plant groups are known from the fossil record, only five lineages are extant: angiosperms and four gymnosperm groups (conifers, cycads, ginkgos, Gnetales). Molecular phylogenetic analyses of seed plants now indicate that the living gymnosperm groups are monophyletic, with Gnetales related to conifers (Doyle, 2006; Hajibabaei et al., 2006; Frohlich \& Chase, 2007). When living and fossil taxa are considered together and constrained into the molecular topology, the combined analysis reveals a revised 'anthophyte clade' consisting of the extinct gymnosperm groups, glossopterids, Pentoxylon, Bennettitales, and Caytonia as sister to angiosperms (Doyle, 2006; Frohlich \& Chase, 2007; Soltis et al., 2008). The monophyly of the extant gymnosperms places them all equally distant from the angiosperms, which means that the lineage that eventually produced angiosperms derived from a common ancestor with extant gymnosperms. In the present article we use this as the phylogenetic framework to review what is known about the evolution of the seed habit. Charles Darwin's studies of seeds have contributed to his ideas on evolution and distribution of plant species (Black, 2009).

Domestication is a complex process along a continuum of human, plant, and animal relationships that often took place over a long time period and was driven by a mix of ecological, biological, and human cultural factors (Gepts et al., 2012; Price and Bar-Yosef, 2011).

\section{Crop evolution and domestication syndromes}

Plant and animal domestication that was initiated approximately 10,000 years ago led to the dramatic evolution of human society and rapid speciation of plants and animals co-evolving with humans (Diamond, 2002). The observation of rapid and drastic phenotypic changes under artificial selection stimulated at least partly Darwin's thinking of the origin of species under natural selection (Darwin, 1859). Despite the fact that the cereal crops were independently domesticated from distantly related grass species, the phenotypic modifications associated with the domestications were strikingly similar. The suites of phenotypic changes that transformed wild grasses into food crops are known as the domestication syndrome (Harlan, 1992 and Hancock, 2004).

Although the exact composition of domestication syndrome traits varies with the crop under consideration, it include a more compact growth habit, increased earliness by alterations in photoperiod sensitivity, reduction or loss of seed dispersal and dormancy, gigantism, reduced toxicity and increased morphological diversity, improved 
threshing ability, reduced tiller number, lightened hull and seed colors, increased tiller erectness, enlarged panicles, increased harvest index, grain size and weight, increased fruit size, changes in branching and stature, change in reproductive strategy and changes in secondary metabolites(Rachel et al, 2012) .

The domestication syndrome may evolve over thousands of generations, as desirable traits are selected for in the agricultural environment and become fixed within the crop genome (Fuller, 2007). Crop plants have continued to change due to selection exerted by ancient and modern plant breeding and cultivation practices. These changes that occurred subsequent to the initial domestication event(s) are known as crop evolution. As a result of both crop domestication and evolution, today's domesticated species are differentiated from their wild ancestors by an assortment of morphological and physiological characteristics (Frary and Doğanlar, 2003).

\section{Plant height and growth habit}

As compared to their wild relatives, crop plants tend to be shorter and have a more compact growth habit. For example, wild beans are vines, whereas the most modified cultivated forms are bush types with fewer branches, a decreased number of nodes and shorter internodes (Pickersgill, 2007).The worldwide acceptance and cultivation of dwarf and semi dwarf wheat and rice lines with reduced lodging was associated with dramatic, unprecedented increases in grain yield (Ikeda et al., 2001). Through comparative genetic analyses of plant height in the cereals both gibberellin acid (GA) sensitive and insensitive dwarfing genes are has been identified by many researchers previously. Mapping of GA sensitive dwarfing genes in wheat and rye suggests that Rht12on the long arm of wheat chromosome 5A is orthologous to Ddw1 on the long arm of the homologous rye chromosome 5R (Borner et al., 1997). For these genes, the mutant (dwarf) phenotype is the result of deletions in the 5 ' portion of the gene. These results indicate that the regulation of growth by GA has been conserved during the evolution of all flowering plants (Laurie and Devos, 2002).

Even though the studies of plant height in other crops are at a less advanced stage, there is evidence that plant height qualitative trait loci (QTL) are also conserved among other species. Lan and Paterson (2001) have been identified five stem length (equivalent to plant height) QTL in Brassica oleracea that have nine potential counterparts in Arabidopsis. The discovery of self-pruning, SP, mutant gene in tomato during its domestication has significant advances for cultivation of the crop. Mutant plants have a compact, erect, determinate growth habit which ensures synchronous fruit set, tillering and allows mechanical harvesting (Pnueli et al., 1998). Tomato has a more primitive growth habit in which the vegetative and reproductive stages alternate because of the mutant gene discovered during domestication. Cereals have fewer branches ('tillers') than their wild counterparts do; the extreme case is maize, which has only one main stem whereas its wild progenitor, called teosinte, has 10-20 branches(Gepts, 2002).

\section{Flowering time}

During domestication, variation in flowering time may have been subject to both deliberate and indirect selection. Direct selection probably resulted from the desire for a plant that produced a crop earlier in the season. Optimization of flowering time maximizes the yield potential of a crop by providing the best environmental conditions for reproductive growth. Flowering time in the cereals is controlled by three different types of genes: photoperiod responding gene, vernalization genes that respond to low temperature and earliness genes that are independent of light and temperature conditions (Snape et al., 2001).

Domesticated of wheat from hot and dry region is photoperiod insensitive that flowers sooner and produces larger seeds than other types (Snape et al., 2001). Interestingly, the barley and wheat genes have been found to govern different responses to day length, which may indicate that the genes are actually distinct and not derived by descent from a common ancestor. However, an alternative explanation is that this difference is simply a reflection of allelic variation in gene expression that has given rise to diverse phenotypes (Laurie, 1997). The recent map-based cloning of an important QTL for photoperiod response in rice, Hd1, has shown that orthology for the trait is not limited to the cereals (Yano et al., 2000).Hdl corresponds to the rice Sel mutant, a homolog of the Arabidopsis constants (CO) gene. As rice is a short-day plant and Arabidopsis is a long-day plant, the same genes are involved in both types of photoperiod response. Reduced photoperiod response is important in Europe and North America, where growing seasons are long (Turner et al., 2005).

Through vernalization flowering will be promoted by exposure to cool temperatures and this trait important for crop domestication and evolution because it allows adaptation to different planting times to obtain the best yield (Snape et al., 2001).In wheat, the difference between winter and spring types is controlled by the Vrn genes and $V r n-A 1$ on chromosome $5 \mathrm{~A}$ seems to be the most important locus for determining the vernalization requirements of European wheat varieties (Snape et al., 2001). According to Laurie (1997) and Borner et al. (1998) this gene has putative orthologs in both rye (Sp1) and barley (Sh2) and conserved during crop domestication and evolution. The spring types lack the vernalization requirement and show different responses to long days. Four flowering time/heading date determining QTLs were mapped on chromosomes 2A, 4B, 5A, and 6B (Peng et al., 2003). QTL on 5A chromosome increase the value of HD and so is responsible for the late flowering of $T$. 
dicoccoides, whereas alleles on chromosomes $2 \mathrm{~A}, 4 \mathrm{~B}$, and $6 \mathrm{~B}$ can accelerate the flowering date.

\section{Inflorescence size and morphology}

Large number of crops has been domesticated through modification of their inflorescence size and morphology. Outstanding example for impact of selection on morphological diversity is brassica and inflorescence of cauliflower has a curd phenotype while that of broccoli has a head phenotype. Both cauliflower (B. oleraceasubsp. botrytis) and broccoli (B. oleracea subsp. italica) have dramatically enlarged inflorescences as compared to their wild relatives (Purugganan et al., 2000). Lan and Paterson (2000) have been found five QTL for the width of the largest cluster within the curd, 12 QTL for the width of the entire curd and 11 QTL for the number of first rank branches in the curd.

Domestication in the cereals also involved changes in inflorescence size and morphology. The wild species of pearl millet have short, narrow spikes while cultivated plants have much longer, wider spikes with a denser arrangement of spikelet (Poncet et al., 2000). Moreover, in barley, central spikelet is fully fertile, but the two lateral spikelet are either staminate or completely sterile in two-rowed barley, while in six-rowed barley all three are fully fertile (Pourkheirandish and Komatsuda, 2007).All wild barleys are two rowed, which is an advantageous for them, since the arrowhead shape of the spikelet at maturity helps it to become buried in the soil once it disarticulates (Bothmer et al. 1995); in addition, the degenerating pair of lateral spikelet form a hook-like structure, which allows its ready attachment to an animal coat, and thus promotes seed dispersal.

\section{Fruit size and morphology}

During the domestication and evolution of fruit crops, selection resulted in increased fruit size and diversified fruit morphology and color. Tomato fruit can be round, blocky, elongated, pear or heart shaped and can be found in colors ranging from green to yellow to pink, orange and red but, the wild one is small, round, red or green fruit. Grandillo et al. (1999) identified a set of fruit weight and shape loci that are shared by cultivated tomato and several of its wild relatives. Three fruit weight QTL identified in eggplant had putative orthologs in tomato. Among these three conserved loci, one (fw2.1) also appeared to have a counterpart in pepper. This QTL is of special interest because it corresponds to the fw2.2 gene of tomato which is important fruit weight QTL identified to date in tomato. This locus has been cloned and is thought to be a negative regulator of cell division (Frary et al., 2000).This locus appears to be conserved in tomato, pepper and eggplant and this imply strong evidence that the gene had significant role in domestication of solanaceae crops.

\section{Organ color and toxic substance}

Organ color also another characteristic that seems to have been conserved during crop domestication and evolution. Pepper's carotenoid biosynthetic pathway genes structural map has been conducted and compared their locations with the positions of QTL and qualitative mutations in tomato and potato (Thorup et al., 2000).This analysis indicated that six of the pepper enzyme loci have putative orthologs in tomato and their map positions correspond to the locations of three fruit color QTL and three tomato carotenoid mutant loci. The gene locus named as lutescent-2 (12), is characterized by delayed red pigment formation and reduced levels of $\beta$-carotene and xanthophyll. Similarly, carotenoid biosynthesis gene, $\beta$ carotenehydroxylase (crtZ), appears to have an orthologous in potato as it maps to a common region with the yellow flesh (Y) mutant of potato which has yellow or orange tubers.

The most significant anthocyanin QTL in eggplant accounted for at least $75 \%$ of variation in fruit color and much of the variation in leaf, stem, prickle and flower corolla anthocyanin levels (Doganlar et al., 2002). This QTL mapped to a position on LG 10 of eggplant that is homologous to regions of chromosomes 5 and 10 in tomato and potato. These regions of tomato and potato harbor five different color mutations. Three of these loci are found in potato and control flower (F) and tuber skin color (Iep and Ico). The two tomato genes, anthocyanin free (af) and anthocyanin gainer (ag), are characterized by the complete absence of and the delayed/altered distribution of anthocyanin in the plant, respectively (Anne and Sami, 2003). Gepts (2002) has been suggested that selection leading to a reduction or loss of toxic compounds of cultivating crops and an example is provided by cassava, where sweet cultivars have a reduced content of a cyanogenic-glucoside that releases the highly toxic cyanic acid.

\section{Seed size and dispersal}

Domestication in seed crops was often accompanied by dramatic increases in seed size/weight and decreases in seed dispersal over their wild type. Increases in seed size are very apparent in the legumes. Greater seed size probably contributed to seedling vigor, and a loss of germination inhibitors would have allowed faster germination. Thin seed-coats also evolved under domestication, as a reduced seed-coat is more permeable to water and results in more rapid germination. Johnson et al. (1996) found that a seed weight QTL associated with Phs, the locus that codes for the most abundant seed storage protein (phaseolin) of a common bean which has a putative ortholog in mung bean. Maughan et al. (1996) identified a different soybean seed weight locus with a potential counterpart in 
cowpea. In the cereals, three seed size loci have putatively orthologous counterparts in rice, maize and sorghum and a total of 23 seed size QTL had been identified and only four had no potential orthologs in at least one of the other species (Paterson et al., 1995).

The problem of seed dispersal/shattering that happens to cultivated crops like cereal, legumes and etc. reduced or eliminated by selection of non-shattering type. Analysis of the genetic control of shattering in these crops has revealed additional examples of conservation of domestication trait gene function. The single locus that controls nearly all of the shattering phenotype in sorghum has potential orthologs in both rice and maize (Paterson et al., 1995). Similarly, seed dispersal loci in pearl millet have putative orthologs in rice, maize and/or sorghum (Poncet et al., 2000; Poncet et al., 2002). In a few cases, crops possess alleles of major genes that disrupt seed shattering (Li et al., 2006) or the protective casing surrounding the seed (Wang et al., 2005) that are not found in the progenitor species. So, for shattering as well as for many other traits, mutations in a limited number of genes were capable of giving rise to the domesticated phenotype. This trait is agriculturally deleterious, and thus transformation of brittle rachis $(\mathrm{Br})$ to non- $\mathrm{Br}$ is perhaps the first sign of domestication in wheat (Peng et al., 2003). Loss of seed shattering is key event in the domestication of major cereals (Konishi et al., 2006).

\section{Glum tenacity and free-threshing}

Glum tenacity is another key trait closely related to them free-threshing habit and is modified by the domestication process in wheat. The wild emmer wheat floret is wrapped by tough glumes that make spikes difficult to thresh, whereas cultivated wheat have soft glumes and are free-threshing. Semi-wild wheat differs from common wheat in glum tenacity (Cao et al., 1997).Genetic analysis showed that at least two genes controlled the free-threshing trait in crosses involving synthetic wheat (Villareal et al., 1996). Jantasuriyarat et al. (2004) identified several QTLs on chromosomes 2A, 2B, 2D, 5A, 6A, 6D, and 7B that significantly affect the free-threshing characteristic. All non-free-threshing wild wheat carries the recessive $q$ allele and all free-threshing tetraploid and hexaploid wheat carry the dominant $\mathrm{Q}$ allele. In T. aestivum, the Q allele supports the formation of square-headed ears with good thresh ability, besides inducing softening of the glumes, reduction of ear length, more spikelet per ear, and toughness of the rachis (Kato et al., 1998, 2003).

\section{Seed dormancy}

Dormancy is inherent block of germination of viable seed under favorable environmental condition. This controls germination timing in response to the seasons and plays an important role in seed plant evolution and adaptation to climatic changes (Leubner-Metzger, 2007). Donohue (2005) suggested that germination timing may strongly influence the rate at which species can expand their range, and may play an important role in determining survival or extinction during climate change. The evolution of larger embryo size likely resulted in occurrence of no dormant seeds; the embryo did not need to grow before germination. It is thought that increased relative embryo size is one of the main determinants (or requirements) for the evolution of other classes of seed dormancy (FinchSavage \& Leubner- Metzger, 2006). Moreover, wild peas display a strong seed dormancy phenotype mediated by water-impermeable seed coats (Abbo et al., 2011, Werker et al., 1979 and Weeden., 2007), whereas domesticated peas germinate readily upon wetting. The study of changes in dormancy with domestication is complicated in many crops; this is due to limited morphological visibility of dormancy-related traits, and limited knowledge of the factors that govern dormancy (Fuller and Allaby, 2009).

\section{Impact and gaps of crop evolution and domestication}

Beginning around $8500 \mathrm{BC}$, the transition from the hunter-gatherer lifestyle to food production enabled people to settle down next to their permanent gardens, orchards and pastures, instead of migrating to follow seasonal shifts in wild food supplies. Food production also led to an explosion of technology, because sedentary living permitted the accumulation of heavy technology (such as forges and printing presses) that nomadic hunter-gatherers could not carry, and because the storable food surpluses resulting from agriculture could be used to feed full-time craftspeople and inventors (Diamond, 2002).

\section{Conclusion}

From the begging of agricultural practices, crops have been playing an important role in human life and that is why scientist concern in studying their origin as well as their difference from the wild ancestors through archeological or genetically analysis method. Early people began altering communities of flora and fauna for their own benefit through other means such as fire-stick farming and forest gardening very early. This brings the concept of evolution and demonstration for the altering crops and this happens due to mutation, immigration, artificial selection, natural selection, and speciation. At the time of domestication and evolution the crop species underwent dramatic morphological and physiological changes. Genetic analysis of the control of these changes indicates that traits related to domestication are controlled by relatively few genes and that these genes often have major effects on plant phenotype. The difference in characters resulted between cultivated crop and the wild ancestors due to 
different factors named as syndromes. Comparative mapping indicates that several genes for important domestication syndrome traits including plant height, flowering time, inflorescence and fruit morphology, organ color, and seed size and dispersal are conserved among different domesticated species.

Generally, as the environment and human interest changed time to time application or using cutting age technologies like molecular techniques to identify appropriate targets and hasten selection of new domesticates among wild germplasm is indispensible. Thus, a wild species that is capable of growth under specific biotic or abiotic stresses could be rapidly domesticated for human use and cultivation.

\section{References}

Anne F and Sami D., 2003. Department of Biology, izmir Institute of Technology, Gulbahce Campus, 35437, Urla, izmir- TURKEY.

Fuller, D.Q. and Allaby, R., 2018. Seed dispersal and crop domestication: shattering, germination and seasonality in evolution under cultivation. Annual plant reviews, pp.238-295.

Beerling D. 2007. The Emerald Planet. How Plants Changed Earth's History. xvi+ 288 pp. Oxford, New York: Oxford University Press. Price£ 14.99 (hard covers).

Borner, A., Korzun, V. and Worland, A.J., 1997. Comparative genetic mapping of loci affecting plant height and development in cereals. In Wheat: Prospects for Global Improvement (pp. 311-314). Springer, Dordrecht.

Bothmer, R., Jacobsen, N., Baden, C., Jorgensen, R. and Linde-Laursen, I.1995. In An Ecogeographical Study of the Genus Hordeum. IBPGR, Rome.

Cantino, P.D., Doyle, J.A., Graham, S.W., Judd, W.S., Olmstead, R.G., Soltis, D.E., Soltis, P.S. and Donoghue, M.J., 2007. Towards a phylogenetic nomenclature of Tracheophyta. Taxon, 56(3), pp.1E-44E.

Cao, W., Scoles, G.J. and Hucl, P., 1997. The genetics of rachis fragility and glume tenacity in semi-wild wheat. Euphytica, 94(1), pp.119-124.

Darwin C,1905. The variation of animals and plants under domestication John Murray, London (popular edition in two volumes), $566 \mathrm{p}$

Darwin C, 1859.On the origin of species by means of natural selection. Jone Murray, London

De Candolle, A. 1959. Origin of Cultivated Plants, 2nd ed. (translated from the 1886 version). Hafner,New York, ny, usa .

Diamond, J., 2002. Evolution, consequences and future of plant and animal domestication. Nature, 418(6898), p.700.

Diamond, J. and Bellwood, P., 2003. Farmers and their languages: the first expansions. Science, 300(5619), pp.597-603.

Doganlar, S., Frary, A., Daunay, M.C., Lester, R.N. and Tanksley, S.D., 2002. Conservation of gene function in the Solanaceae as revealed by comparative mapping of domestication traits in eggplant. Genetics, 161(4), pp.1713-1726.

Donohue, K., 2005. Niche construction through phenological plasticity: life history dynamics and ecological consequences. New Phytologist, 166(1), pp.83-92

Doyle, J.A., 2006. Seed ferns and the origin of angiosperms. The Journal of the Torrey Botanical Society, pp.169209.

Feldman, M. and Kislev, M.E., 2007. Domestication of emmer wheat and evolution of free-threshing tetraploid wheat. Israel Journal of Plant Sciences, 55(3-4), pp.207-221.

Finch-Savage, W.E. and Leubner-Metzger, G., 2006. Seed dormancy and the control of germination. New phytologist, 171(3), pp.501-523.

Flint-Garcia, S.A., 2013. Genetics and consequences of crop domestication.Journal of agricultural and food chemistry, 61(35), pp.8267-8276.

Frary, A. and Doğanlar, S., 2003. Comparative genetics of crop plant domestication and evolution. Turkish Journal of Agriculture and Forestry, 27(2), pp.59-69.

Frohlich MW, Chase MW. 2007. After a dozen years of progress the origin of angiosperms is still a great mystery. Nature 450: 1184-1189.

Fuller, D.Q., 2007. Contrasting patterns in crop domestication and domestication rates: recent archaeobotanical insights from the Old World. Annals of Botany, 100(5), pp.903-924.

Grandillo, S., Ku, H.M. and Tanksley, S.D., 1999. Identifying the loci responsible for natural variation in fruit size and shape in tomato. Theoretical and Applied Genetics, 99(6), pp.978-987.

Hajibabaei M, Xia J, Drouin G. 2006. Seed plant phylogeny: Gnetophytes are derived conifers and a sister group to Pinaceae. Molecular Phylogenetics and Evolution 40: 208-217.

Hammer, K. 1984. Domestications and syndrome. Kulturpflanze 32, 11-3

Hancock, J.F., 2012. Plant evolution and the origin of crop species. CABI.

Hancock, J.F., 2005. Contributions of domesticated plant studies to our understanding of plant evolution. Annals of Botany, 96(6), pp.953-963. 
Harlan, J.R., 1992. Crops and man (No. Ed. 2). American Society of Agronomy.

Ikeda, A., Ueguchi-Tanaka, M., Sonoda, Y., Kitano, H., Koshioka, M., Futsuhara, Y., Matsuoka, M. and Yamaguchi, J., 2001. slender rice, a constitutive gibberellin response mutant, is caused by a null mutation of the SLR1 gene, an ortholog of the height-regulating gene GAI/RGA/RHT/D8. The Plant Cell, 13(5), pp.9991010 .

Jantasuriyarat, C., Vales, M.I., Watson, C.J.W. and Riera-Lizarazu, O., 2004. Identification and mapping of genetic loci affecting the free-threshing habit and spike compactness in wheat (Triticum aestivum L.). Theoretical and Applied Genetics, 108(2), pp.261-273.

Johnson, W.C., Menéndez, C., Nodari, R., Koinange, E.M., Magnusson, S., Singh, S.P. and Gepts, P., 1996. Association of a seed weight factor with the phaseolin seed storage protein locus across genotypes, environments, and genomes in Phaseolus-Vigna spp.: Sax (1923) revisited. J. Quant. Trait Loci, 2(5).

Kalisz, S. and Kramer, E.M., 2008. Variation and constraint in plant evolution and development. Heredity, 100(2), p.171.

Konishi, S., Izawa, T., Lin, S.Y., Ebana, K., Fukuta, Y., Sasaki, T. and Yano, M., 2006. An SNP caused loss of seed shattering during rice domestication. Science, 312(5778), pp.1392-1396.

Lan, T.H. and Paterson, A.H., 2000. Comparative mapping of quantitative trait loci sculpting the curd of Brassica oleracea. Genetics, 155(4), pp.1927-1954.

Laurie, D.A., 1997. Comparative genetics of flowering time. In Oryza: From Molecule to Plant (pp. 167-177). Springer, Dordrecht.

Laurie, D.A. and Devos, K.M., 2002. Trends in comparative genetics and their potential impacts on wheat and barley research. Plant molecular biology, 48(5-6), pp.729-740.

Leubner-Metzger, G., 2002. Seed after-ripening and over-expression of class I $\beta$-1, 3-glucanase confer maternal effects on tobacco testa rupture and dormancy release. Planta, 215(6), pp.959-968.

Li, C., Zhou, A. and Sang, T., 2006. Rice domestication by reducing shattering. science, 311(5769), pp.1936-1939.

Maxted, N. and Given, D., 2005. Conservation of Crop Genetic Resources. The Cultural History of Plants, pp.413429.

Maughan, P.J., M.A. Saghai-Maroof and G.R. Buss. 1996. Molecularmarker analysis of seed-weight: genomic locations, gene action and evidence for orthologous evolution among three legume species. Theor. Appl. Genet. 93: 574-579.

Murphy, D.J., 2007. People, plants \& genes: the story of crops and humanity. Oxford University Press on Demand.

Parmesan, C., 2006. Ecological and evolutionary responses to recent climate change. Annual Review of Ecology, Evolution, and Systematics, pp.637-669.

Paterson, A.H., Lin, Y.R., Li, Z., Schertz, K.F., Doebley, J.F., Pinson, S.R., Liu, S.C., Stansel, J.W. and Irvine, J.E., 1995. Convergent domestication of cereal crops by independent mutations at corresponding genetic loci. Science, 269(5231), pp.1714-1718.

Stewart, W.N. and Rothwell, G.W., 1993. Paleobotany and the evolution of plants. Cambridge University Press.

Peng, J., Ronin, Y., Fahima, T., Röder, M.S., Li, Y., Nevo, E. and Korol, A., 2003. Domestication quantitative trait loci in Triticum dicoccoides, the progenitor of wheat. Proceedings of the National Academy of Sciences, 100(5), pp.2489-2494.

Pickersgill, B., 2007. Domestication of plants in the Americas: insights from Mendelian and molecular genetics. Annals of botany, 100(5), pp.925-940.

Poncet, V., Lamy, F., Devos, K.M., Gale, M.D., Sarr, A. and Robert, T., 2000. Genetic control of domestication traits in pearl millet (Pennisetum glaucum L., Poaceae). Theoretical and Applied Genetics, 100(1), pp.147159.

Pourkheirandish, M. and Komatsuda, T., 2007. The importance of barley genetics and domestication in a global perspective. Annals of Botany, 100(5), pp.999-1008.

Price, T.D. and Bar-Yosef, O., 2011. The origins of agriculture: new data, new ideas: an introduction to supplement 4. Current Anthropology, 52(S4), pp.S163-S174.

Purugganan, M.D., Boyles, A.L. and Suddith, J.I., 2000. Variation and selection at the CAULIFLOWER floral homeotic gene accompanying the evolution of domesticated Brassica oleracea. Genetics, 155(2), pp.855-862.

Meyer, R.S., DuVal, A.E. and Jensen, H.R., 2012. Patterns and processes in crop domestication: an historical review and quantitative analysis of 203 global food crops. New Phytologist, 196(1), pp.29-48.

Rimando, T.J., 2004. Crops science 1: fundamentals of crop science. UP Hosbernes, University Publication Office.

Ross-Ibarra, J., Morrell, P.L. and Gaut, B.S., 2007. Plant domestication, a unique opportunity to identify the genetic basis of adaptation. Proceedings of the National Academy of Sciences, 104(suppl 1), pp.8641-8648.

Vavilov, N. I. 1992. Origin and Geography of Cultivated Plants . University Press, Cambridge, uk

Wang R-L, Stec A, Hey J, Lukens L, Doebley J, 1999:The limits of selection during maize domestication Nature pp 236-239.

Wang, H., Nussbaum-Wagler, T., Li, B., Zhao, Q., Vigouroux, Y., Faller, M., Bomblies, K., Lukens, L., and 
Doebley, J.F. 2005.The origin of the naked grains of maize. Nature 436, 714-719.

Zohary, D. and Hopf, M., 2000. Domestication of plants in the Old World: the origin and spread of cultivated plants in West Asia. Europe, and the Nile Valley Oxford University Press, New York. 